\title{
Banning tobacco sponsorship: replacing tobacco with health messages and creating health-promoting environments
}

C D'Arcy J Holman, Robert J Donovan, Billie Corti, Geoffrey Jalleh, Shirley K Frizzell, Addy M Carroll

\begin{abstract}
Objective-To evaluate the replacement of Western Australian tobacco sponsorship with health promotion sponsorship by the Western Australian Health Promotion Foundation (known as "Healthway"), following the Tobacco Control Act 1990.

Design-Process measures of performance were collected from 25 tobacco replacement projects (sponsorship by Healthway of sport, racing, and arts groups previously supported by tobacco companies) and 727 other health sponsorship projects, that is, new sponsorship provided by Healthway to these groups. Cross-sectional survey data were obtained from 917 respondents at tobacco replacement and 2352 at other sponsorship venues.
\end{abstract}

Setting-Sport, racing, and arts venues sponsored by the Western Australian Health Promotion Foundation (Healthway) in 1991-95.

Main outcome measures-Population reach, occasions of media publicity, healthy structural changes, cognitivel attitudinal impact of health messages, and the prevalence of five health-risk behaviours.

Results-Tobacco replacement and other sponsorship projects achieved comparable performance in publicity for health messages and in healthy structural change, but replacement projects achieved a fourfold higher level of direct population reach for a given amount of funding. Structural change towards a smoke-free environment occurred more often in tobacco replacement projects and a permanent smoke-free policy was achieved in $47 \%$ of projects, compared with $15 \%$ in other sponsorship projects. The prevalence ratio of current smoking at tobacco replacement venues was 1.86 (95\% confidence interval 1.62 to 2.04 ) relative to other sponsorship venues. There was evidence of higher cognitive resistance to health messages at venues previously sponsored by tobacco companies.

Conclusions-A comprehensive ban on tobacco sponsorship linked to health promotion activities funded by tobacco tax delivers potential public health benefits that exceed those achieved by prohibition of tobacco sponsorship alone. Tobacco replacement venues offer opportunities for environmental modification, promo- $\overparen{\curvearrowright}$ tion of anti-smoking messages, and targeting groups that are hard to reach.

(Tobacco Control 1997;6:115-121)

Keywords: tobacco sponsorship; tobacco tax; legislation; health sponsorship

\section{Introduction}

The sponsorship of sport, racing, and the arts provides an effective medium through which sponsors can achieve high levels of exposure for their products in return for financial support. ${ }^{12}$ The connection between sport and tobacco goes back a century, when trading cards with pictures of cricket and baseball heroes appeared in British and American packets of cigarettes. ${ }^{3}$ Large-scale tobacco sponsorship of sport, racing, and to a lesser degree the arts, has grown steadily in many countries in the last 15 years, in line with the promotional opportunities provided by large crowds, extensive media coverage, and the capacity to circumvent direct advertising bans. ${ }^{3-7}$ Given 8 these developments and the accumulation of evidence on the adverse influence of tobacco advertising and sponsorship on the uptake of smoking in children, ${ }^{89}$ the anti-tobacco movement has become increasingly active in lobbying for legislation to prohibit all forms of o promotion of tobacco products, including sponsorship. ${ }^{1011}$

Health promotion foundations are an Australian invention designed to deal with the o public health and political problems of tobacco $N$ sponsorship. ${ }^{12}$ Attempts to ban tobacco $\mathrm{\omega}^{\circ}$ promotion in Western Australia in 1982 and 1983 failed primarily because of fears about 0 the adverse impact on sport, racing, and arts organisations in receipt of tobacco? sponsorship. ${ }^{13}$ A possible solution first arose in ${ }^{7}$ Victoria, where a comprehensive ban on $\frac{\vec{D}}{\mathbb{D}}$ tobacco advertising and sponsorship was $\frac{\rho}{\circ}$ linked to an increase in tobacco tax and the $\propto$ establishment of the Victorian Health Promotion Foundation. ${ }^{14}$ "VicHealth" pro- o vided sponsorship funds to sport, racing and arts organisations, as well as grants for health promotion projects and grants for research. ${ }^{14} \rightleftharpoons$ Similar measures followed in South Australia, the Australian Capital Territory, and Western Australia. ${ }^{11}{ }^{15-17}$

The Western Australian Health Promotion Foundation (known as Healthway), funded by 
a levy on the wholesale distribution of tobacco products, began early in 1991. Established under tobacco control legislation that outlawed the direct or indirect public promotion of tobacco products, Healthway provided replacement sponsorship to sport, racing, and arts groups previously supported by tobacco companies ("tobacco replacement projects"), as well as new sponsorship to these groups ("other sponsorship projects"). When Healthway provides sponsorship funds, it simultaneously awards a sponsorship support grant to an independent health agency ("health sponsor") to promote a health message-for example: Quit; Be smoke free; Drinksafe; Eat more fruit and veg -at the sport, arts, or racing event. For smaller projects, a sponsorship support " $k i t$ " is provided directly by Healthway. Efforts are made also to create a healthy environment at events through structural changes, such as the introduction of smoke-free areas, safe practices in the serving of alcohol, and provision of healthy food choices.

The promotional and environmental supports purchased through health sponsorship are the latest addition to a comprehensive approach to public health issues such as tobacco control supported by the Western Australian government since 1983 (known as the "Quit" programme, "Drinksafe" programme, etc). The whole-of-government programmes include legislative measures, public education including mass media campaigns, public policy development on product pricing and availability, and community development strategies.

The Western Australian Tobacco Control Act required that, for an initial period of five years, Healthway must give priority to organisations and individuals (other than manufacturers or wholesalers of tobacco products) who had suffered hardship or foregone benefits as a result of a banned tobacco sponsorship. Under these terms, from 1990-91 to $1993-94$, Healthway provided replacement sponsorship to 33 sport, racing, and arts organisations, valued at $\mathrm{A} \$ 2.5$ million over four years. ${ }^{18}$ New sponsorship arrangements were negotiated with these organisations in which, instead of promoting tobacco brand names, they were required to promote health messages through signage, give-aways, incidental advertising, personal endorsements, hospitality, and opportunities for interactive displays; and through structural changes including the provision of smoke-free areas.

There has been disquiet among health, sport, racing, and arts interests that a consequence of the Tobacco Control Act was to "reward" organisations previously receiving tobacco sponsorship by giving them higher priority for Healthway funds than groups that had previously resisted or had been unable to attract tobacco sponsorship. ${ }^{18}$ There have been concerns also that Healthway's negotiating position may have been compromised by the legislative imperative to buy out at the same level as the previous tobacco company involvement. Thus, during the forced buy out, Healthway may have paid a premium for a comparatively modest return in health promotion activities arising from the sponsored event or organisation. With the period for preferential treatment of cases for replacement sponsorship coming to an end, and sponsorship contracts coming up for possible renewal on an equal footing with other sponsorship applications, the question arose as to whether tobacco replacement projects represented good future value for money compared with the alternative of additional projects involving other forms of sponsorship.

Because health sponsorship through Healthway is new, the Health Promotion Development and Evaluation Program was established as an independent academic unit to evaluate the foundation's activities. ${ }^{18}$ Several components of our evaluation strategy have been reported previously. ${ }^{19-26}$ In this paper, we use data from Healthway's system of project evaluation, known as Graduated Project Evaluation (GPE), to describe the health promotion outputs achieved by 25 tobacco replacement projects evaluated by June 1995, and to compare their performance with that of other sponsorship projects.

\section{Methods}

GRADUATED PROJECT EVALUATION

The GPE system consisted of four evaluation levels (basic, process, impact, and outcome) and 10 sets of output measures. ${ }^{1926}$ The requirements of GPE were progressive in that projects assigned to any level reported the measures at that level plus the measures at all preceding levels. The main criterion for assignment of GPE levels was the amount of sponsorship: the larger the amount, the higher the level of evaluation required. Outcome evaluation, the fourth GPE level, was applied only to large health promotion intervention projects. It was not used in sponsorship projects due to the technical limitations of measuring an effect of a single sponsorship beyond the immediate impact of health messages on spectators and participants. ${ }^{19}$ Also excluded from this study were the publication, (community) development, educational, and target measures, because of their peripheral relevance to the evaluation of tobacco replacement projects. ${ }^{19} 26$

\section{COLLECTION AND ANALYSIS OF BASIC AND} PROCESS MEASURES

Standard proformas were completed by sponsorship recipients on each project. The forms for sponsorship projects were organised so that the sport/racing/arts group was responsible for recording the population and publicity measures and the health sponsor was responsible for the remainder of basic and process measures with the exception of the contractual evaluation scores (see below). A total of 752 statistical evaluations were completed on all sponsorship projects by June 1995, of which 25 were completed on tobacco replacement projects.

The five basic and process measures used in this research were as follows. ${ }^{1926}$ 
Contractual evaluation score

This was assigned by Healthway managers using a six-point scale of how outputs from the completed projects measured up against the expectations documented in the contract.

\section{Population reach}

The term "reach" referred only to persons actually attending events and did not include persons exposed indirectly through the mass media. It was defined as the total number of attendances of organisers/performers/players, participants, and spectators. For a series of events, such as a season of football, attendances were summed over all events covered by the sponsorship.

\section{Occasions of publicity}

Separate measures were used to count the occasions of publicity containing the health message in mass media outlets. "Major media" were defined as the national and statewide press, six major radio stations, and four major television stations. Other outlets with smaller audience or circulation size were defined as "minor media".

\section{Structural changes}

Six areas of structural change are sought by Healthway: smoke-free areas, healthy catering (provision of low-fat, low-sugar, low-salt foods, fresh fruit and vegetables), sun protection measures (shaded spectator areas and protective clothing), safe practices in the serving of alcohol (including provision of lowor reduced-alcohol beverages) and improved access of disadvantaged groups and the physically disabled. Changes were defined as "short-term" (adopted only for the duration of the project or event), "marginal" (occurred as a result of developing and refining existing policies), or "permanent" (long-term change resulting from the project).

\section{High-visibility promotional benefits}

Specific promotional benefits were obtained in the following areas: general profile such as naming rights and presentation rights; signage including perimeter signage and official clothing; personal acknowledgment by the commentator, players, or other celebrities; bulk materials such as promotional leaflets and programme advertising; hospitality including complimentary seating for opinion leaders and association of sponsor with catering; and interactive activities such as campaign demonstrations or displays. Promotional benefits were grouped into these six categories for the purpose of assessing their degree of visibility ("low", "medium", or "high").

COLLECTION AND ANALYSIS OF IMPACT MEASURES Impact measures were collected from 3269 spectators and participants, aged 16 or more years, at 42 sponsorship projects classified at GPE level 3 (917 respondents at six tobacco replacement projects; 2352 respondents at 36 other sponsorship projects). To receive a level 3 classification, the total value of the sponsorship exceeded $A \$ 25000$ and the part of the funds available to the health sponsor-that is, the "sponsorship support grant" explained earlier-was at least $\mathrm{A} \$ 7000$. The present results arose from impact surveys conducted between July 1992 and June 1994, according to predetermined sponsorship evaluation guidelines. ${ }^{18}$

The impact data were obtained using a set of standard survey instruments. Separate instruments were used depending on the nature of the event, its location, and the target group. Generally, at sport/racing events the instrument was interviewer-administered, whereas at in arts events, where there was less time to $\vec{\circ}$ administer questionnaires, interviewers screened participants, but the instrument was self-administered. The instruments were designed to elicit data on demographics and of five health-risk behaviours, and to measure two is or more of a hierarchy of cognitive/attitudinal $\overrightarrow{\vec{G}}$ effects concerning the impact of the health message. ${ }^{1927}$ The following questions were representative of those contained in the survey instruments to obtain cognitive/attitudinal measures.

- Unprompted recall: Do you recall seeing or hearing any messages or slogans about health being announced or displayed at today's/tonight's event?

- Prompted recognition (interviewer-administered questionnaires only): Here are a number of health messages. Just tell me which of these, if any, you recall being associated with today's/tonight's event.

- Comprehension: What do you think the health message [relevant message] means? What is it actually saying?

- Acceptance: Would you say that you agree, disagree, or have no feelings either way about the message [relevant message]?

- Intention: When you saw or heard the health message [relevant message] associated with today's/tonight's event, or at a previous event, did you think about anything at all related to that message?

- Action (restricted to those attending a previous event in a series): Did you do anything, anything at all, as a result of being aware of the health message [relevant message] at a previous event?

The questionnaire items were selected from $N$ the advertising, consumer, and market N research literature. ${ }^{28-30}$ As they were all single items, we could not estimate their reliability. However, the validity of the items has been established by their predictive use in many $\stackrel{\oplus}{\rightarrow}$ studies in advertising, consumer behaviour, $T$ and psychology, such that they have become standard measures.

The survey sample size for individual $\stackrel{\mathbb{D}}{\circ}$ projects ranged from 17 to 504 respondents (mean 121), the minimum sample size having 8 been determined by the dollar value and type of project. ${ }^{19}$ Health messages promoted at the

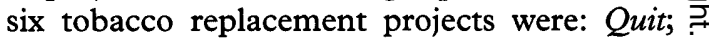
Beat diabetes 2-be activeleat less fat; and Fitness fights arthritis. Additional messages promoted at other sponsorship projects included: Let's clear the air; Be smokefree; Eat more fruit and veg; Eat less fat; Be active every day; Protect yourself in 
Table 1 Distributions of tobacco replacement ("Rep") and other sponsorship ("Other") projects completed in 1991-95 according to amount of funding and project type

\begin{tabular}{|c|c|c|c|c|c|c|c|c|}
\hline \multirow[b]{3}{*}{ Project type } & \multicolumn{8}{|c|}{ Amount of funding } \\
\hline & \multicolumn{2}{|c|}{$\leqslant \$ 10000$} & \multicolumn{2}{|c|}{$\$ 10001-25000$} & \multicolumn{2}{|c|}{$\$ 25001-100000$} & \multicolumn{2}{|c|}{$\geqslant \$ 100001$} \\
\hline & $\operatorname{Rep}$ & Other & $\operatorname{Rep}$ & Other & $\operatorname{Rep}$ & Other & $R e p$ & Other \\
\hline Sport & 5 & 297 & 1 & 42 & 2 & 32 & 2 & 5 \\
\hline Racing & 2 & 18 & 2 & 2 & 4 & 1 & 5 & 0 \\
\hline Arts & 1 & 182 & $\overline{1}$ & 82 & 0 & 60 & 0 & 6 \\
\hline
\end{tabular}

the sun; Be sun wise; Play it safe; and Child safety is no accident.

The five health-risk behaviours measured included current smoking and current unsafe alcohol intake, with the latter defined as more than four/two drinks in males/females respectively, taken on any one of the last seven days. Exercise behaviour during the last week was classified as "none", "some", or "as recommended" by the National Heart Foundation, that is, exercise every day in the last week. History of any sunburn was ascertained from the last 12 months to reduce seasonal bias and was classified as "no sunburn in the last 12 months" and "sunburnt in the last 12 months". The health department of Western Australia recommended that the public consume at least two pieces of fruit and five portions of vegetables every day. Thus, fruit and vegetable consumption was classified as "low on both", "low on one", and "both as recommended".

\section{STATISTICAL ANALYSIS}

Table 1 shows the distributions of tobacco replacement and other sponsorship projects according to the amount of funding and project type (sport/racing/arts sponsorship). Compared with other projects, replacement projects were more likely to involve a racing sponsorship, less likely to involve an arts sponsorship, and more likely to be assigned one of the higher sponsorship levels. The average funds committed to a tobacco replacement project were $A \$ 153840$ (\$450-1 240507 ), compared with A $\$ 13409$ ( $\$ 130-188000)$ for other sponsorship projects. The four largest tobacco replacement sponsorships were made to the Turf Club, Trotting Association, Australian Rugby League, and Australian Football League.

Given that project outputs varied according to the amount of funding and project type, ${ }^{19}{ }^{26}$ these confounding variables were adjusted in the analyses of tobacco replacement and other sponsorship projects. For basic and process measures this was done using multiple linear regression. ${ }^{31}$ Each output measure was configured as the dependent variable, while replacement project status was denoted by a $0 / 1$ indicator variable. The regression coefficient of this term was the mean difference in the output measure between tobacco replacement and other sponsorship projects. Amount of funding was then represented in all models as continuous linear and quadratic terms; both terms were found to be highly significant in most models. Binary $0 / 1$ indicator variables were tried for racing and arts projects in each model, but neither was found to add new information and these terms were not retained.

For the impact measures obtained from surveys of spectators and participants, the distribution of other sponsorship data according to GPE level and project type was matched to the distribution of tobacco replacement project data by use of a balanced system of weights. The restriction of impact evaluation to the higher GPE levels constrained the variation in the amount of funding per project and thus adjustment through a modelling technique was unnecessary. Approximate confidence intervals for prevalence ratios of health-risk behaviours were obtained from the assumption of log-normal sampling distributions and a Taylor series first-order approximation of variance. ${ }^{32}$

\section{Results}

BASIC AND PROCESS MEASURES

Table 2 gives a comparison of GPE output measures obtained from tobacco replacement and other sponsorship projects. The mean contractual evaluation score assigned to tobacco replacement projects was 3.9. This approximates closely to the normative score of 4 , defined as "The outputs of the project were consistent with or in the vicinity of those required by the contract." Contractual performance was essentially the same as in other sponsorship projects, which averaged a score of 3.8 .

The 25 replacement projects had a total reach of over 1.3 million attendances, averaged at 50847 per project. This was some eightfold higher than the average reach of other sponsorship projects and, even after adjustment for the larger amount of funding received by replacement projects, the difference remained of practical and statistical significance.

Tobacco replacement projects outperformed other sponsorship projects on both major and minor publicity measures, due in large part to horse racing. Reference to the health message was made on a major radio station each time a race was called. As with the direct reach of projects, the level of media coverage was strongly associated with the amount of sponsorship received. After adjustment for amount of funding, there was almost no difference in occasions of minor media publicity and a much reduced, although empirically positive, difference in major media exposure.

One or more health promotive structural changes were achieved at sport, racing, or arts venues in $60 \%$ of tobacco replacement projects and $67 \%$ of other sponsorship projects. When the average numbers of changes were compared, other sponsorship projects performed somewhat better in achieving short-term or marginal reforms, whereas the tobacco replacement projects produced more permanent changes. None of these differences was significant.

Healthway's foremost priority in achieving environmental change has been the extension of smoke-free areas at sport, racing, and arts venues. Before Healthway's involvement, none 
Table 2 Comparison of graduated project evaluation output measures obtained from tobacco replacement projects and other sponsorship projects funded by Healthway in 1991-95

\begin{tabular}{|c|c|c|c|c|}
\hline \multirow[b]{2}{*}{ Measure } & \multirow{2}{*}{$\begin{array}{l}\text { Tobacco } \\
\text { replacement } \\
\text { projects }(A)\end{array}$} & \multirow{2}{*}{$\begin{array}{l}\text { Other } \\
\text { sponsorship } \\
\text { projects }(B)\end{array}$} & \multicolumn{2}{|c|}{ Difference $^{a}(A-B)$} \\
\hline & & & Crude & Adjusted $^{b}$ \\
\hline \multicolumn{5}{|c|}{$\begin{array}{l}\text { Basic and process measures } \\
\text { ( } \mathrm{n}=25 \text { tobacco replacement projects and } 727 \text { other sponsorship projects) }\end{array}$} \\
\hline Mean contractual evaluation score & 3.9 & 3.8 & 0.1 & 0.1 \\
\hline Mean population reach & 50847 & 6151 & $44696^{\star \star \star}$ & $19075^{\star \star}$ \\
\hline \multicolumn{5}{|l|}{ Mean occasions of publicity } \\
\hline Minor media & 36.3 & 16.9 & $19.4^{\star}$ & -0.4 \\
\hline Major media & 175.9 & 10.5 & $165.4^{\star \star \star}$ & 14.6 \\
\hline \multicolumn{5}{|l|}{ Mean number of structural changes } \\
\hline Short-term or marginal & 0.68 & 0.90 & -0.22 & -0.24 \\
\hline Permanent & 0.32 & 0.21 & 0.11 & 0.12 \\
\hline Mean number of high visibility promotional benefits & 0.64 & 1.08 & $-0.44^{\dagger}$ & -0.15 \\
\hline \multirow{2}{*}{\multicolumn{5}{|c|}{$\begin{array}{l}\text { Impact measures } \\
(\mathrm{n}=917 \text { tobacco replacement respondents and } 2352 \text { other sponsorship respondents) }\end{array}$}} \\
\hline \multicolumn{2}{|l|}{ Proportion of targeted respondents with } & & & \\
\hline Any awareness (prompted or unprompted) & 0.76 & 0.61 & $0.15^{\star \star \star}$ & $0.14^{\star \star \star}$ \\
\hline Unprompted recall & 0.51 & 0.54 & $-0.03^{\dagger}$ & $-0.07^{\star \star \star}$ \\
\hline Comprehension (in those aware) & 0.87 & 0.85 & 0.02 & 0.01 \\
\hline Acceptance (in those comprehending) & 0.81 & 0.92 & $-0.11^{\star \star \star}$ & $-0.11^{\star \star \star}$ \\
\hline Intention (in those accepting) & 0.06 & 0.09 & $-0.03^{\star}$ & $-0.04^{\star}$ \\
\hline Action (in those forming an intention at a previous event) & 0.11 & 0.25 & $-0.14^{\star \star \star}$ & $-0.15^{\star \star \star}$ \\
\hline
\end{tabular}

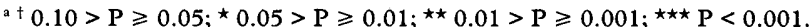

${ }^{b}$ Adjusted for the total amount of sponsorship funding; see text.

'The sample size available for analysis varied across measures.

of the tobacco replacement venues had a smoke-free policy, compared with $24 \%$ of venues receiving other sponsorship project funding. When settings were excluded in which a smoke-free policy was already in place or was not applicable, Healthway succeeded in gaining a change towards a smoke-free environment in $93 \%(14 / 15)$ of possible instances at tobacco replacement venues and $79 \%(284 / 358)$ at other sponsorship venues $(\mathrm{P}=0.185)$. The proportions achieving a permanent smoke-free policy were $47 \%$ and $15 \%$, respectively $(P=0.001)$.

Promotional measures were recorded on 17 replacement projects and 230 other sponsorships assigned to GPE level 2 or higher. The average number of high-visibility promotional benefits was lower in tobacco replacement projects than in other sponsorship projects although, after adjustment for amount of funding, the difference was reduced and could have been explained by chance.

\section{IMPACT MEASURES}

Table 2 also gives the results of impact surveys conducted at six tobacco replacement and 36 other sponsorship projects, evaluated at GPE level 3. A higher proportion of the 917 respondents at replacement projects, compared with respondents at other sponsorships, were aware of the health message promoted at the event $(76 \%$ compared with $61 \%)$. The greater awareness of health messages at tobacco replacement venues was entirely due to higher prompted recognition; unprompted recall was slightly lower at replacement venues. Among those aware, comprehension of the health message was about the same in the two types of project, but the higher forms of cognitive response, involving acceptance of the health message, the formation of an intention and early behavioural action were reduced in respondents interviewed in tobacco replacement projects.

\section{HEALTH-RISK BEHAVIOURS}

Table 3 shows the prevalence of health-risk behaviours in respondents aged 16 years and older. The most conspicuous difference between the two survey populations was the higher prevalence of current smoking at tobacco replacement venues compared with other sponsorship venues (prevalence ratio $=$ $1.86 ; 95 \% \mathrm{CI}=1.62-2.04)$. People attending tobacco replacement projects were also more likely to be unsafe drinkers and slightly more likely not to exercise as recommended. However, tobacco replacement respondents had lower levels of suboptimal fruit and vegetable consumption or poor sun protection, than other sponsorship respondents.

\section{Discussion}

In this study, tobacco replacement and other sponsorship projects achieved comparable performance in publicity for health messages and in healthy structural change, but replacement projects achieved a fourfold higher level of

Table 3 Prevalence of health risk behaviours in respondents aged $\geqslant 16$ years attending Healthway-sponsored sports, arts, and racing events comparing tobacco replacement and other sponsorship projects

\begin{tabular}{|c|c|c|c|c|}
\hline \multirow[b]{2}{*}{ Health risk behaviour } & \multirow{2}{*}{$\begin{array}{l}\text { Tobacco replacement } \\
\text { sponsorship projects }(n=917) \\
\text { Prevalence }(\%)\end{array}$} & \multirow{2}{*}{$\begin{array}{l}\text { Other sponsorship } \\
\text { projects }(n=2505) \\
\text { Prevalence }(\%)\end{array}$} & \multicolumn{2}{|c|}{ Prevalence ratio } \\
\hline & & & Estimated & $95 \% C I$ \\
\hline Smoking & 38 & 21 & 1.82 & $1.62-2.04$ \\
\hline Unsafe alcohol drinking & 51 & 40 & 1.26 & $1.17-1.37$ \\
\hline Suboptimal fruit or vegetable consumption & 69 & 78 & 0.88 & $0.84-0.93$ \\
\hline Suboptimal exercise & 70 & 66 & 1.07 & $1.01-1.12$ \\
\hline Poor sun protection & 53 & 62 & 0.86 & $0.81-0.93$ \\
\hline
\end{tabular}


direct population reach for a given amount of funding. Structural change towards a smoke-free environment was achieved more often in tobacco replacement projects and a permanent smoke-free policy was achieved three times more often than in other sponsorship projects. The prevalence of current smoking at tobacco replacement venues was higher relative to other sponsorship venues and there was evidence of higher cognitive resistant to health messages at venues previously sponsored by tobacco companies.

Several limitations should be kept in mind in the interpretation of these results. Not all output measures recorded in GPE were meticulously validated and it is possible that sponsorship recipients overestimated measures such as population reach in an effort to gain favour with their funding agency. However, given the greater security of sponsorship funds flowing to tobacco replacement, it is difficult to conceive how such a bias might have caused the fourfold higher reach of replacement projects. Structural changes such as smokefree policies and areas, as well as visible promotional benefits, were carefully verified by health sponsors through site inspections. Appropriate caution should be exercised in the interpretation of the self-reported impact data obtained from respondent surveys at events. Although the items correspond with standard practice in commercial marketing research, their psychometric properties have not been assessed rigorously. It should also be acknowledged that awareness of a health message does not equate with behaviour change. Nevertheless, immediate cognitive effects such as awareness ranging through to the formation of an intention are a necessary precursor to behaviour change and, therefore, important results to achieve and to measure.

Despite the limitations of this specific evaluation of tobacco replacement projects, it would appear that the results do provide supporting evidence for the value of health promotion foundations. Legislative initiatives in Europe and, most recently, the entire Commonwealth of Australia, have banned tobacco advertising and sponsorship without provision of replacement sponsorship funding. ${ }^{811}$ In at least two other instances, in California and in earlier regulatory action in Western Australia, an increase in tobacco tax has been used to fund a statewide anti-smoking campaign in the absence of a ban on sponsorship. ${ }^{13} 33$ A likely strength of the health promotion foundation model is that it combines two forms of tobacco control initiative into one integrated strategy. The combination is useful because the venues formerly targeted by the tobacco industry offer opportunities for environmental modification, social marketing of anti-smoking and other health messages, and targeting groups that are hard to reach. ${ }^{22}$

There appear to be three benefits of the health promotion foundation model. The first is the buy-out of tobacco sponsorship itself, with the result that large numbers of children and adults are no longer exposed to the promotion of a product that is injurious to health. The results show that not only has tobacco sponsorship ceased, but tobacco replacement venues have led the move towards smoke-free areas and non-smoking policies. More replacement projects than other sponsorships contributed to control of passive smoking through structural change, and the reforms achieved in replacement venues were more likely to be permanent. This probably reflects the rigour applied by health agencies to these sponsorships in view of their previous history. Public support for a smoke-free environment at sports, racing, and arts venues has gathered momentum in association with Healthway's efforts. ${ }^{21}$ Important milestones have been the state's baseball and football leagues' voluntary decisions to declare the outdoor seating areas at their premier venues to be non-smoking areas. ${ }^{18}{ }^{21}$ The latter venue, which is the home of two Australian football league teams, one having been sponsored previously by the tobacco industry, is the largest and most popular sporting ground in Western Australia. The next step in the progression of structural change, now under active pursuit from Healthway in return for sponsorship dollars, is restriction on the sale of tobacco products at venues.

Secondly, tobacco replacement projects outperformed other sponsorship projects in reaching larger audiences and groups of spectators, a difference that was not explained solely by the higher average cost of a replacement project. Other differences in basic and process measures, after adjustment for the amount of funding, were variable in direction and could have been explained by chance. Our overall impression is that the two types of sponsorship projects achieved comparable performance, but that the tobacco replacement projects represented better value for money in the number of people reached at sponsored events. Given the marketing resources available to the tobacco industry, it is perhaps not surprising that it had successfully engaged the best of the available sponsorship opportunities.

A third advantage of tobacco replacement projects is the opportunity they present to reach large numbers of current smokers and, to a lesser extent, people who consume alcohol at unsafe levels. The observation that the prevalence of current smoking was 1.82 times higher in the populations attending tobacco replacement venues raises the possibility that previous tobacco promotion at these venues had been successful in initiating or maintaining smoking behaviour among regular patrons. Alternatively, it may reflect an association of underlying personality correlates of smoking with a predilection to attend large racing and sports events, or a calculated decision by tobacco companies to promote their brand names at venues with a high prevalence of current smoking. Regardless of the true explanation(s), the public health implications are clear: it is appropriate to give highest priority to tobacco control activities at replacement venues.

In other research, we have compared the cognitive and attitudinal responses to 
anti-smoking messages between smokers and non-smokers. ${ }^{18}$ This showed that smokers had a greater awareness of anti-smoking messages than non-smokers, but, not unexpectedly given their defence mechanism, were less accepting of these messages. The results are consistent with those observed in this study at tobacco replacement venues. Spectators and participants at these venues had a higher level of recognition of health messages, including anti-tobacco messages, compared with populations at other sponsorship venues, and had a similar level of comprehension, but proved less accepting of the message and more resistant to the formation of an intention to act on the message. Nevertheless, by combining the hierarchical system of impact measures in table 2, it is estimated that $0.4 \%$ $(=0.76 \times 0.87 \times 0.81 \times 0.06 \times 0.11)$ of respondents attending a tobacco replacement venue took some form of action as a result of the health message promoted at the event. The corresponding estimate for respondents at other sponsorship venues was $1.1 \%$. The difference is more than compensated by the effective fourfold higher population reach of tobacco replacement projects independent of the amount of sponsorship funding received, and the need to persist with anti-smoking messages at replacement venues given the risk factor profiles of those in attendance.

\section{Conclusions}

The linkage of a comprehensive ban on the promotion of tobacco products in Western Australia with the creation of a health promotion foundation to receive and disburse increases in tobacco taxes may deliver potential benefits to public health that go beyond what could have been achieved through prohibition of sponsorship alone. Opportunities arising in the aftermath of tobacco sponsorship offer health promotion practitioners access to the groups most recently exposed to tobacco promotion. Eventually, it may be possible to reverse the adverse effects of tobacco sponsorship; and for the time being, therefore, tobacco replacement projects would appear to offer good value for money.

The Health Promotion Development and Evaluation Program is an independent academic programme supported by the Western Australian Health Promotion Foundation.

1 Okter T. Exploitation: the key to sponsorship success. Eur Res 1988;16:77-86.

2 Sandler DM, Shani D. Olympic sponsorship vs 'ambush' marketing: who gets the gold? F Advertising Res 1989;29:9 14.

3 Blum A. Tobacco industry sponsorship of sports: a growing dependency. In: Durston B, Jamrozik $\mathrm{K}$, eds. Tobacco and
health 1990 - the global war. Proceedings of the seventh world health 1990 - the global war. Proceedings of the seventh world conference on tobacco and health. Pe

4 Raw M. Massive free BBC tobacco promotion. BMF 1990; 301:1061.
5 Bonn D. New Zealand: cigarettes and sport. Lancet 1991;337:1469.

6 Blum A. The Marlboro Grand Prix. Circumvention of the television ban on tobacco advertising. $N$ Engl f Med 1991; 324:913-7.

7 Connolly GN, Orleans CT, Blum A. Snuffing tobacco out of sport. Am f Public Health 1992;82:351-3.

8 Rimpelä MK, Aaro LE, Rimpelä AH. The effects of tobacco sales promotion on initiation of smoking-experiences from Finland and Norway. Scand $\mathcal{F}$ Soc Med 1993;49 Suppl:5-23.

9 US Department of Health and Human Services. Preventing tobacco use among young people. A report of the Surgeon General. Atlanta, Georgia: Public Health Service, Centers for Disease Control and Prevention, Office on Smoking and Health, 1994 (US Government Printing Office No S/ 017-001-00491-0.)

10 Simpson D. Paris and beyond. Tobacco Control 1994;3:302

11 Furlong $R$. Tobacco advertising legislation and the sponsorship of sport. Aust Business Law Review 1994:22:159-89.

12 Daube M Health promotion foundations in Australia. Health Prom $\mathcal{f}$ Aust 1993;3:3.

13 Musk AW, Shean R, Woodward S. Legislation for smoking control in Western Australia. BMF 1985;290:1562-5.

14 Galbally R. The Victorian Health Promotion FoundationVic Health. Health Prom f Aust 1993;3:4-5.

15 Court $M$. The South Australian Health Promotion Foundation-Foundation S.A. Health Prom f Aust 1993; 3:25-6.

16 Thompson K. ACT Health Promotion Fund. Health Prom $\mathcal{F}$ Aust 1993;3:70-71

17 Carroll A. The Western Australian Health Promotion Foundation-Healthway. Health Prom $f$ Aust 1993;3:42-3.

18 Holman CDJ, Donovan RJ, Corti B. Report of the evaluation of the Western Australian Health Promotion Foundation. of the Western Australian Health Promotion Foundation. Department of Public Health and Graduate School of Management, The University of Western Australia, Perth, 1994.

19 Holman CDJ, Donovan RJ, Corti B. Evaluating projects funded by the Western Australian Health Promotion Foundation: a systematic approach. Health Prom Int 1993; 8:199-208.

20 Donovan RJ, Corti B, Holman CDJ, West D, Pitter D. Evaluating sponsorship effectiveness. Health Prom $₹$ Aust 1993;3:63-7.

21 Corti B, Holman CDJ, Donovan RJ, et al. Public attitudes to smoke-free areas in sports venues. Med $\mathcal{F}$ Aust 1995; 162:612.

22 Oddy WH, Holman CDJ, Corti B, Donovan RJ. Epidemiologic measures of participation in community health promotion projects. Int $\mathcal{F}$ Epidemiol 1995;24:1013-21.

23 Corti B, Holman CDJ, Donovan RJ, Frizzell SK, Carroll AM. Using sponsorship to create healthy environments in sport, racing and arts venues. Health Prom Int 1995; 10:185-97.

24 McGuiness D, Corti B, Holman CDJ, Donovan RJ. Do health promotion foundations give more money to health promotion, sport, the arts and research?-The case of Healthway. Health Prom $\mathcal{f}$ Aust 1995;5:4-8.

25 Corti B, Donovan RJ, Holman CDJ, Coten N, Jones SJ. Using sponsorship to promote health messages to children. Health Educ Behav 1997;24:276-86.

26 Holman CDJ, Donovan RJ, Corti B, Jalleh G, Frizzell SK Carroll AM. Evaluating projects funded by the Western Australian Health Promotion Foundation: first results. Health Prom Int 1996;11:75-88.

27 Donovan RJ, Robinson L. Using the mass media in health promotion: The Western Australian immunisation campaign. In: Hall R Richters J eds. Immunisation: the old and paign. In: Hall R, Richters J, eds. Immunisation: the old and

28 Rossiter JR, Percy L. Advertising and promotion management. New York: McGraw-Hill, 1987.

29 Haley RI. The ARF copy research validity project, final report. In: Transcript proceedings of the 7 th $A R F$ copy research
workshop. New York: Advertising Research Foundation, 1990.

30 Malhotra NK. Marketing research: an applied orientation. Englewood Cliffs, New Jersey: Prentice-Hall, 1993.

31 Norusis MJ. SPSS for Windows. Base system user's guide, release 5.0. Chicago: SPSS, 1992.

32 Rothman KJ. Modern epidemiology. Boston: Little, Brown, 1986.

33 Bal DG, Kizer KW, Felten PG, Mozar HN, Niemeyer D. Reducing tobacco consumption in California. Development of a statewide anti-tobacco use campaign. $\mathfrak{F} A M A$ 1990;264:1570-4. 